\title{
Robust mine closure development and maintenance
}

\author{
I.C. Mitchell Outback Ecology, Australia
}

\begin{abstract}
Mine closure planning is becoming increasingly more rigorous both nationally and internationally. Greater expectations are being placed on industry from the community, industry itself and from within government to ensure mining and in particular rehabilitation and closure are completed in an ecologically sustainable manner.

From the community perspective, these expectations have come from a growing awareness of environmental issues and the need for an increase in environmental protection. The mining industry understands and accepts the responsibility it has for mine rehabilitation and closure. The industry recognises that in failing to address rehabilitation and closure issues correctly, its reputation is affected. The industry also recognises that to gain access to future resources it needs to demonstrate that it can close mines effectively (DITR, 2006a).

From the government perspective, a greater emphasis is being placed on mine closure planning to ensure processes are in place and mines are closed in a way so as to not cause unacceptable liability to the government (Western Australian (WA) Department of Mines and Petroleum (DMP), 2011).

This paper will present an overview of the WA 'Guidelines for Preparing Mine Closure Plans', introduced in July 2011 and jointly prepared by the DMP and the Environmental Protection Authority (EPA).

A component of these guidelines requires companies to undertake a review and re-submit their Mine Closure Plans (MCP) every three years. The guidelines require ongoing collection and analysis of significant amounts of rehabilitation and closure data, and require proponents to detail how this information and data will be managed. It will therefore be critical for mines to improve their data management capabilities.
\end{abstract}

The paper will provide an insight into the development of systematic and robust MCPs, and the maintenance and refinement of closure plans through the operating phase and beyond. The paper will also discuss the use of electronic tools that assist and streamline the data management and review process to save time and resources for mining companies.

\section{$1 \quad$ Introduction}

Mine closure planning is becoming increasingly more rigorous both nationally and internationally. Greater expectations are being placed on industry to ensure mining and in particular rehabilitation and closure is completed in an ecologically sustainable manner. In most countries, the role of government in mine closure is expanding, largely because of its role in enacting and implementing appropriate policy and legislation to ensure the expected standards of closure are being met (Clark and Cook Clark, 1999).

Increasing expectations for mine closure standards were recognised in Western Australia (WA) in 2010 by amendments to the Mining Act 1978. In July 2011, the Guidelines for Preparing Mine Closure Plans (MCPs) were enacted. The guidelines were developed by the WA Department of Mines and Petroleum (DMP) and the Environmental Protection Authority (EPA).

The guidelines were designed to assist operators to create robust and systematic MCPs with a focus on the need to commence mine closure rehabilitation and closure planning early in the mine's life. This has placed a requirement on mines to collect, store and manage data and information at the planning phase and throughout the mine life cycle to assist with the rehabilitation, closure and relinquishment process. These requirements now make it even more beneficial for mines to have systems in place that can manage the 
data efficiently and also report on it effectively to assist with the updates to the mine closure plans that are now required.

This paper will discuss the development of systematic and robust MCPs, and their maintenance and refinement through operations and beyond. The paper will demonstrate how the use of electronic tools can assist and streamline the data management and review process to save time and resources for mining companies and potentially government reviewers and other associated stakeholders. This would reduce the burden for all stakeholders of the more rigorous legislative controls not just within WA but around the world.

\section{Western Australian mine closure plan guidelines overview}

The guidelines for preparing MCPs stipulate that a MCP be submitted to the DMP for approval as part of Mining Proposal applications received after 30 June 2011. Furthermore, the guidelines require retrospective MCPs for mines that had a Mining Proposal and/or a Notice of Intent (NOI) approved under the Mining Act 1978 prior to 1 July 2011.

The ultimate aim of the guidelines is to support the legislative amendments in improving the performance of mine closure in WA. This is accomplished through the implementation of a detailed planning process to ensure mines can be closed, decommissioned and rehabilitated in an ecologically sustainable manner, consistent with agreed post mining outcomes and land uses, and without unacceptable liability to the WA government.

The legislative amendments encourage mining companies to develop a systematic, integrated and adequately costed approach, thus reducing overall costs and risk. It has been recognised that a detailed MCP is an essential management tool to ensure mines are adequately rehabilitated upon closure and relinquished in a cost effective manner. The guidelines assist mining companies to identify the risks associated with mine closure early and to ensure mitigation strategies are factored into financial provisioning for closure Furthermore, the guidelines are designed to ensure the development of MCPs through the early phases of a mine's life and their continued management and refinement through construction, operations and closure (Figure 1).

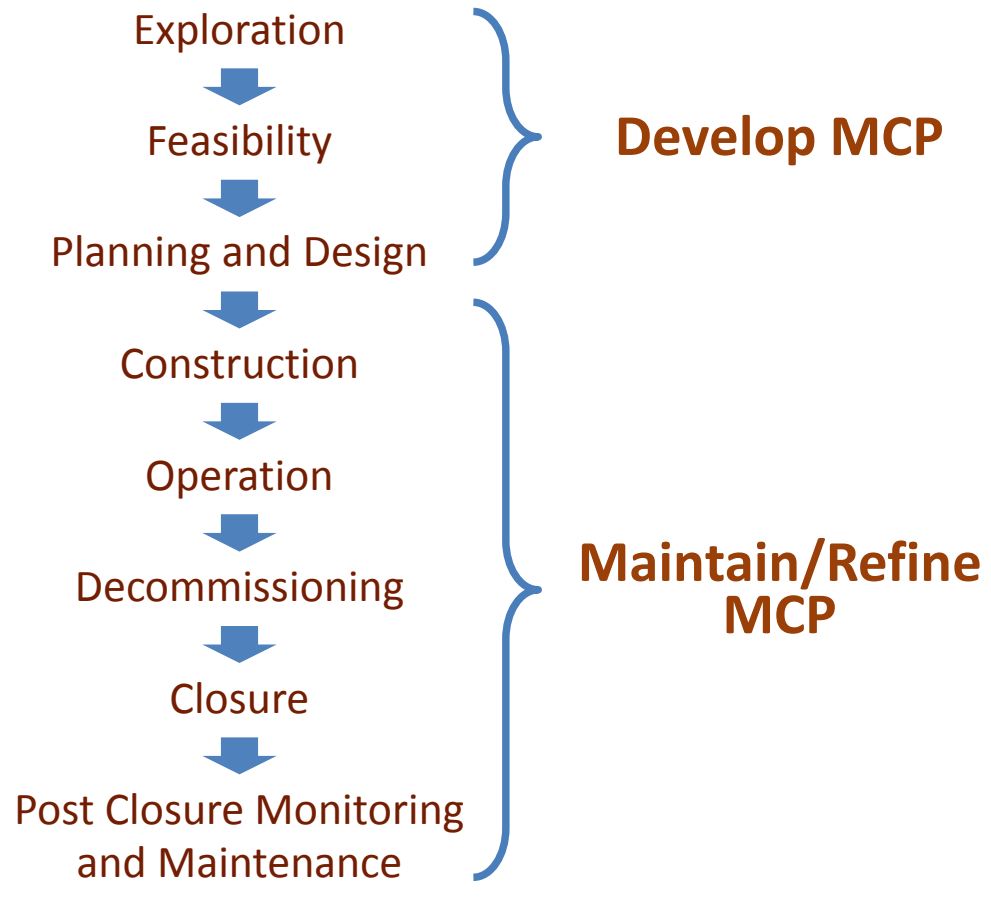

Figure 1 Mine life cycle in relation to the development and refinement of MCPs 


\section{Development of an MCP}

For maximum effectiveness, a robust MCP should be integrated into the initial phases of the mine life (exploration, feasibility and planning and design). This is critical to achieve successful closure outcomes (Bentel, 2009). Core planning activities which are required to take place for the successful development of a MCP include:

- Stakeholder consultation.

- Baseline studies.

- Material characterisation.

- Development of post-mining land use and closure objectives.

- Consideration of completion criteria.

- Risk assessment.

- Consideration of domains.

- Financial provisioning.

\subsection{Consulting stakeholders}

Stakeholder consultation is a central component of successful mine closure planning. Stakeholders can be differentiated into two categories, primary and secondary. Primary stakeholders are those with a vested interest in the closure planning processes and outcomes, while secondary stakeholders include those who have an association with a mine, though not as directly as the primary stakeholders.

Effective stakeholder consultation is an inclusive process and is critical to ensure that all stakeholders are able to contribute to the closure planning process. The degree of dialogue and influence (and the level of engagement) this process has, will vary within and between mines (Figure 2). Consultation approaches cover a spectrum from low levels of engagement (providing information to stakeholders) through to empowering stakeholders in the decision-making process (Western Australian Department of State Development, 2009). Traditionally only low levels of engagement were required, for example a mining company simply communicating with the local community it's plans whereas now high levels of engagement are required to ensure local stakeholders have a full understanding of impacts and are included in the decision making process.

\subsection{Data collection}

Having sufficient environmental baseline information is essential to support closure planning in the feasibility phase. Mining proposals, including MCPs are most likely to be challenged because of an insufficient understanding of the baseline environmental information, ranging from water quality, hydrology, and geochemical data to flora and fauna data. This data can be used to understand the premining environment as well as establish a local and regional context for determining the potential impacts of the mine.

The collection of pre-mining environmental information is integral to establishing completion criteria, and will help to ensure those criteria are achievable at the end of the mines life.

\subsection{Post-mining land use and closure objectives}

An important aspect of closure planning is defining the post-mining land use and related closure objectives. MCPs should identify post-mining land use(s) and set out mine specific closure objectives consistent with those land use(s) (DMP, 2011). The post-mining land use(s) must be:

- Relevant to the environment in which the mine will operate, or is operating.

- Achievable in the context of post-mining land capability. 
- Acceptable to the key stakeholders.

- Ecologically sustainable in the context of local and regional environment.

The closure objectives should reflect the agreed post-mining land use and also the commitments and policies of the mining company, together with those of regulators, and other stakeholders. Closure objectives are designed to be reviewed over the life of the mine to reflect the expectations of the stakeholders. It is anticipated that the closure objectives will cover a range of aspects including safety, pollution, landform stability and rehabilitation.

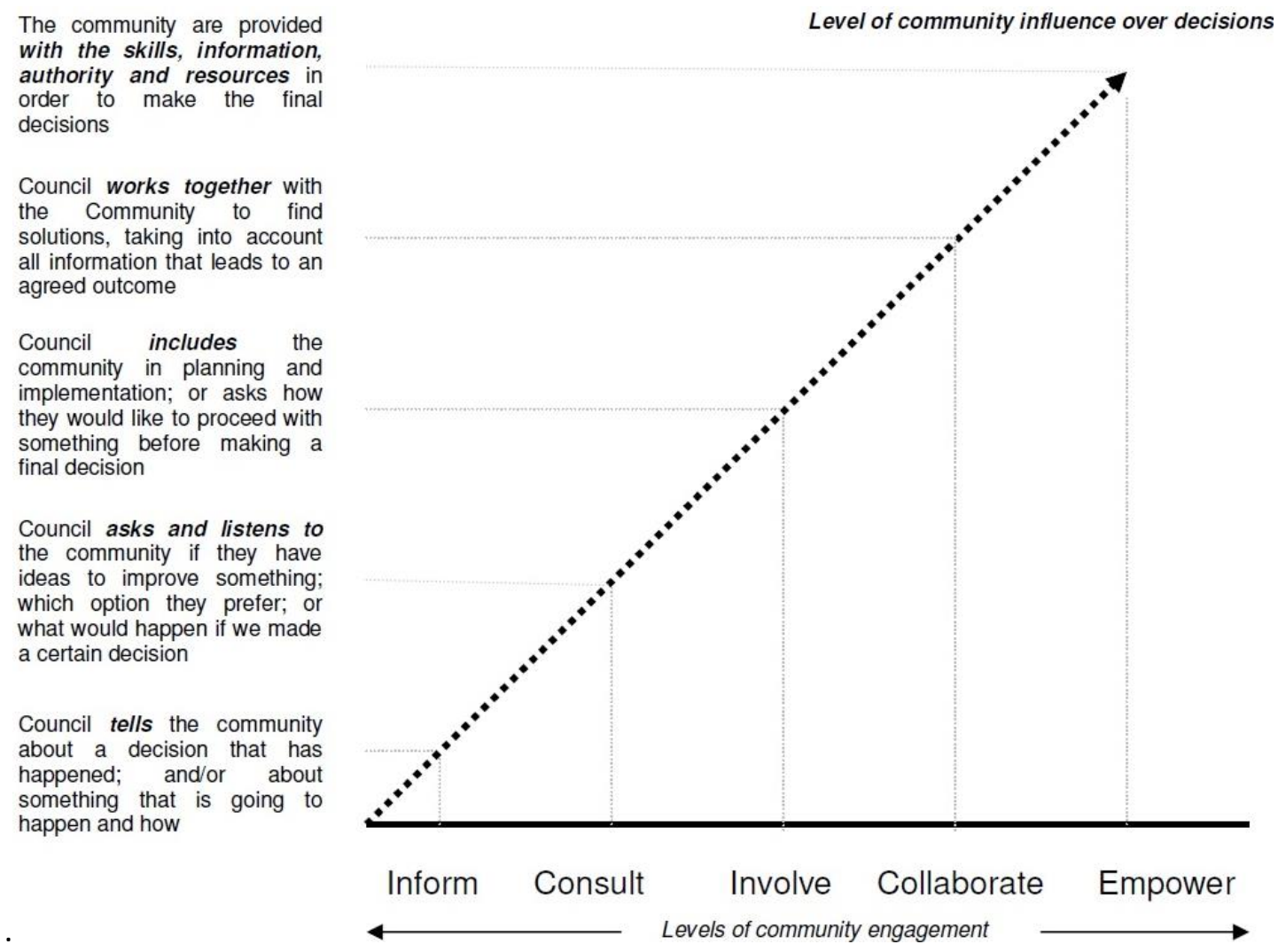

Figure 2 Levels of stakeholder engagement and influence in the consultation process (South Australian Government, 2007)

\subsection{Completion criteria}

Closure objectives need to be supported by completion criteria, which are necessary to provide a framework for measuring rehabilitation and closure success. The agreed land use(s) and closure objectives establish the basis for developing completion criteria and performance indicators. Completion criteria are defined as agreed standards or levels of performance, which demonstrate successful closure of a mine (DITR, 2006b). Once achieved, they demonstrate to the mining company, regulators and other stakeholders that bond and/or lease relinquishment can occur (Friedel et al., 2012).

Completion criteria must be site specific and reflect the unique set of environmental, social and economic circumstances of the mine. They should also be quantitative and capable of objective verification (ANZMEC/MCA, 2000). Completion criteria can be defined by the S.M.A.R.T acronym, in that they are should be specific, measurable, achievable, relevant, and timely. When developing criteria based on the S.M.A.R.T philosophy, some simple questions can be asked to determine if the criteria being developed are acceptable. 


\section{Specific}

Is the criterion directly related to the intent of the objective, and is there a specific element to be measured? For example an objective for restored vegetation may be supported by a completion criterion requiring a particular density of native plant species. This criterion should be linked to an appropriate monitoring approach to define density of that species.

\section{Measurable}

Is the monitoring approach to measure the criterion practicable, readily repeatable and allow for external verification?

\section{Achievable}

Is on-going monitoring cost-effective, physically achievable and is the data analysis able to be conducted by suitably qualified personnel?

\section{Relevant}

Is the criteria relevant to the mine and is the data being collected relevant to the criteria?

\section{Timely}

Can the monitoring, analysis and reporting be done in an appropriate timeframe and are expectations of the time it may take for rehabilitation establishment realistic?

\subsection{Characterisation of soil materials and mined wastes}

One of the major components associated with successful mine closure involves the rehabilitation of waste landforms. Issues may arise from surface instability, inadequate vegetation establishment and growth, and/or the inappropriate placement of chemically-hostile materials. Characterising waste materials and soils before constructing the landform is a key step to maximising the likelihood that the final landform satisfies stakeholder expectations (Jasper and Braimbridge, 2008).

In detailing the importance of waste characterisation the guidelines state that:

"Comprehensive characterisation of materials (including soils and wastes) is critical to successful progressive rehabilitation and should start during the exploration phase and continue throughout all stages of the mine." (DMP, 2011)

As a minimum, analysis of the following materials is recommended:

- Soils - to identify those soil types and horizons which are best suited to supporting a selfsustaining vegetative cover, and to identify potential plant growth limitations.

- Overburden and waste rock - to identify material capable of supporting plant growth that could be used in the root zone, as well as waste material that may not be suitable for rehabilitation purposes and thus requires specific placement in the body of the landform.

\subsection{Risk assessment}

A structured risk assessment framework and a meaningful stakeholder consultation process enable mine closure risks and opportunities to be identified early in the planning process (DITR, 2006a). A risk assessment is a required element of mine closure planning in WA. The risk assessment process enables closure risks to be identified, their potential environmental impacts, likelihood and consequence, mitigation measures and management of residual risk. The outcomes of the process can be used to prioritise closure planning, rehabilitation works and monitoring throughout the life of the mine. The main elements of risk management are described below (DITR, 2006a):

- Communicate and consult. 
- Establish the context.

- Identify risks.

- Analyse risks.

- Evaluate risks.

- Treat risks.

- Monitor and review.

\subsection{Identification of mine domains}

A recommended first step in developing an MCP is to segregate the site into specific areas, or closure domains. A domain is classified as a group of landform(s) or infrastructure that have similar rehabilitation and closure requirements and objectives (DMP, 2011). Each domain should be treated as a separate entity for detailed work plans, but within an overall plan which addresses the integration of the domains (DTIR, 2006a).

\subsection{Financial provisioning}

A summary of the mine closure financial provisioning methodology is to be included in all new MCPs in WA. The summary must clearly show the costing methodology used, assumptions and the financial processes to demonstrate that the costs of meeting the closure outcomes identified in the plan has been understood, and adequate financial provisions have been made. The closure cost estimates must be regularly reviewed to reflect changing circumstances and to ensure that the accuracy of closure costs will be refined.

\section{$4 \quad$ Maintenance of an MCP}

As per the WA guidelines MCPs are required to be updated at least every three years. Therefore, management and continued collection of the data acquired during the development phase of the MCP is critical in maintaining the robustness and effectiveness of the closure plan.

Tasks required to be undertaken to ensure the information obtained in the development phase is managed and enhanced during this phase of the mine life include:

- Continued stakeholder consultation.

- Continued data collection/monitoring of progressive rehabilitation and of the surrounding environment.

- Research and investigations to resolve limitations and ensure appropriate outcomes.

- Financial provisioning.

- Technical documentation.

\subsection{Continued stakeholder consultation}

Regular stakeholder consultation should be conducted post MCP development to ensure communication channels remain open and that any changes to mine plans or changes to identified stakeholders are communicated effectively. A summary of the consultation process should be documented within a Stakeholder Consultation Register.

\subsection{Data collection/monitoring}

Data established during development of the MCP need to be updated and maintained throughout the operation of the mine and beyond in order to ensure the relevance of the MCPs and its compliance with to 
regulations. The collection of environmental data should be continued and expanded throughout the project life, and include as an example:

- Continuation from baseline surveys.

- Rehabilitation monitoring.

- Tailings monitoring.

- Ground and surface water monitoring.

This data will assist in refining closure objectives and completion criteria.

\subsection{Research/investigative tasks}

Targeted research, field trials and investigations can be an important complement to baseline data, allowing spatial and temporal variations in the surrounding environments to be identified and rehabilitation outcomes optimised (DITR, 2006b). Investigative/research tasks that can be conducted include:

- Landform rehabilitation trials.

- Soils/waste investigations.

- Sampling/monitoring during operations (e.g. tailings).

- Surface and ground water hydrology.

\subsection{Updated financial provisioning}

Once the initial closure costs have been established as part of the initial MCP closure cost estimates are required to be regularly reviewed to reflect changing circumstances and to ensure that the accuracy of closure costs will be refined and improved with time. The process and methodology for calculating the cost estimates must be transparent and verifiable (DMP, 2011).

\subsection{Technical documentation}

Technical documentation and reports developed during the construction and operating phases are important resources for planning and reporting on closure. They should be saved and stored with the other rehabilitation and closure related documentation created during the development of the MCP. Examples of relevant documents may include Tailings Storage Facility as-built documents and Annual Environmental Reports.

\section{Tools to facilitate the information management process}

The development and maintenance of a MCP leads to a substantial body of information collected through each mining phase. This information needs to be accessed to assist with the implementation of rehabilitation and closure tasks.

Electronic systems which can be used to manage, maintain and update this body of information will become more important as the amount of data increases and the information that is required by regulators grows. Further benefits of electronic management systems include the ability to store all data in a centralised location. These systems can also hold data in perpetuity, and potentially provide online or static output (information and data) as required (DMP, 2011). Electronic systems that enable companies to manage this information include:

- Consolidated databases.

- Geographical Information Systems (GIS).

- Electronic task registers. 


\subsection{Consolidated databases}

Like many industries, the mining industry relies on large amounts of data. Correct data management therefore is critical to the successful running of a mining operation. Historically data may have been stored in spreadsheets. The primary function of spreadsheets is to analyse data and sort list items, not for the long-term storage of data. Databases should be used for this function as they enable greater flexibility for storage, sorting and reporting of information. Furthermore, databases allow for greater efficiencies in multi-user data access and editing, quality control, integration with spatial data, and web-based access to data (US EPA, 2011). Rehabilitation and closure related data that can be stored within a database include:

- Baseline studies.

- Exploration database information.

- Topsoil management history and planning information.

- Weed management data.

- Material characterisation data.

- Rehabilitation monitoring data.

- Stakeholder consultation information.

- Biological monitoring history and data.

- Updated closure cost information.

- Related technical information and reports.

\subsection{GIS systems}

GIS systems are a good way to store and retrieve domain specific data. GIS systems allow users to view domains and their corresponding features.

Typical GIS data is based upon operational domains rather than final closure domains. It has been historically difficult to keep this information up to date as mine plans change. GIS based systems that enable rehabilitation and closure data to be updated as mines change therefore can help mitigate this issue. Figure 3 which shows the tailings storage facility 'feature' within the 'landform' domain for the Challenger mine displayed within the PRAC ${ }^{\circledR}$ (Progressive Rehabilitation and Closure) System developed by Outback Ecology.

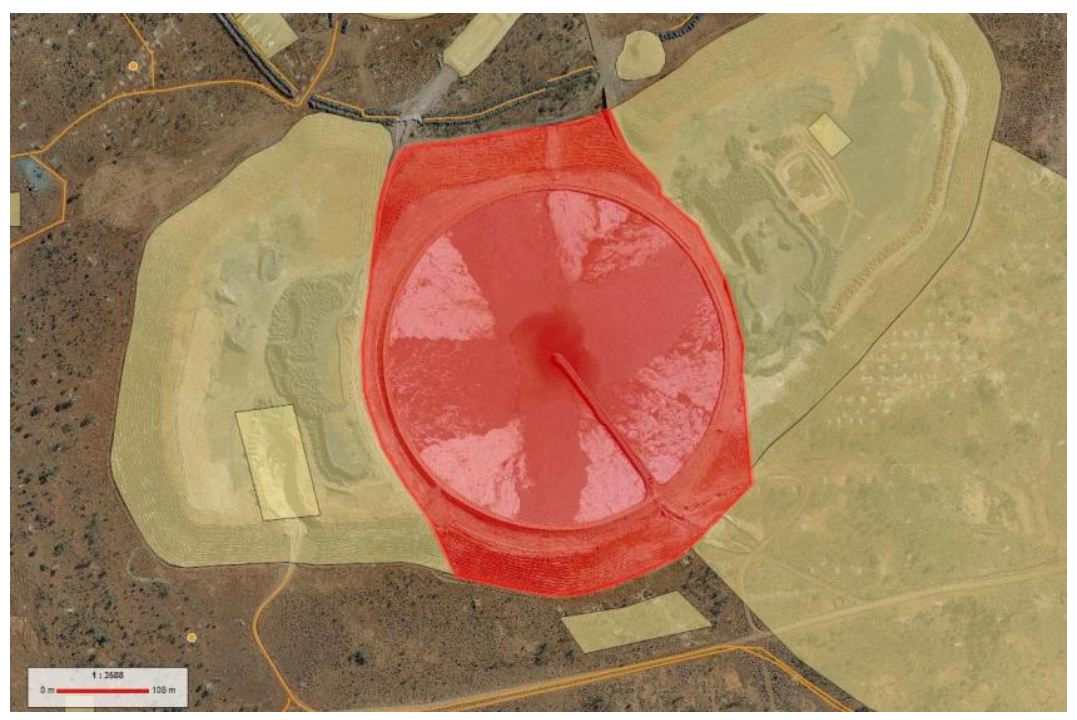

Figure 3 Tailings storage facility highlighted within the PRAC ${ }^{\circledR}$ system for the Challenger Mine 
By clicking on the highlighted feature the user then has access to information and documentation relating to it, making information access straightforward (Figure 4).

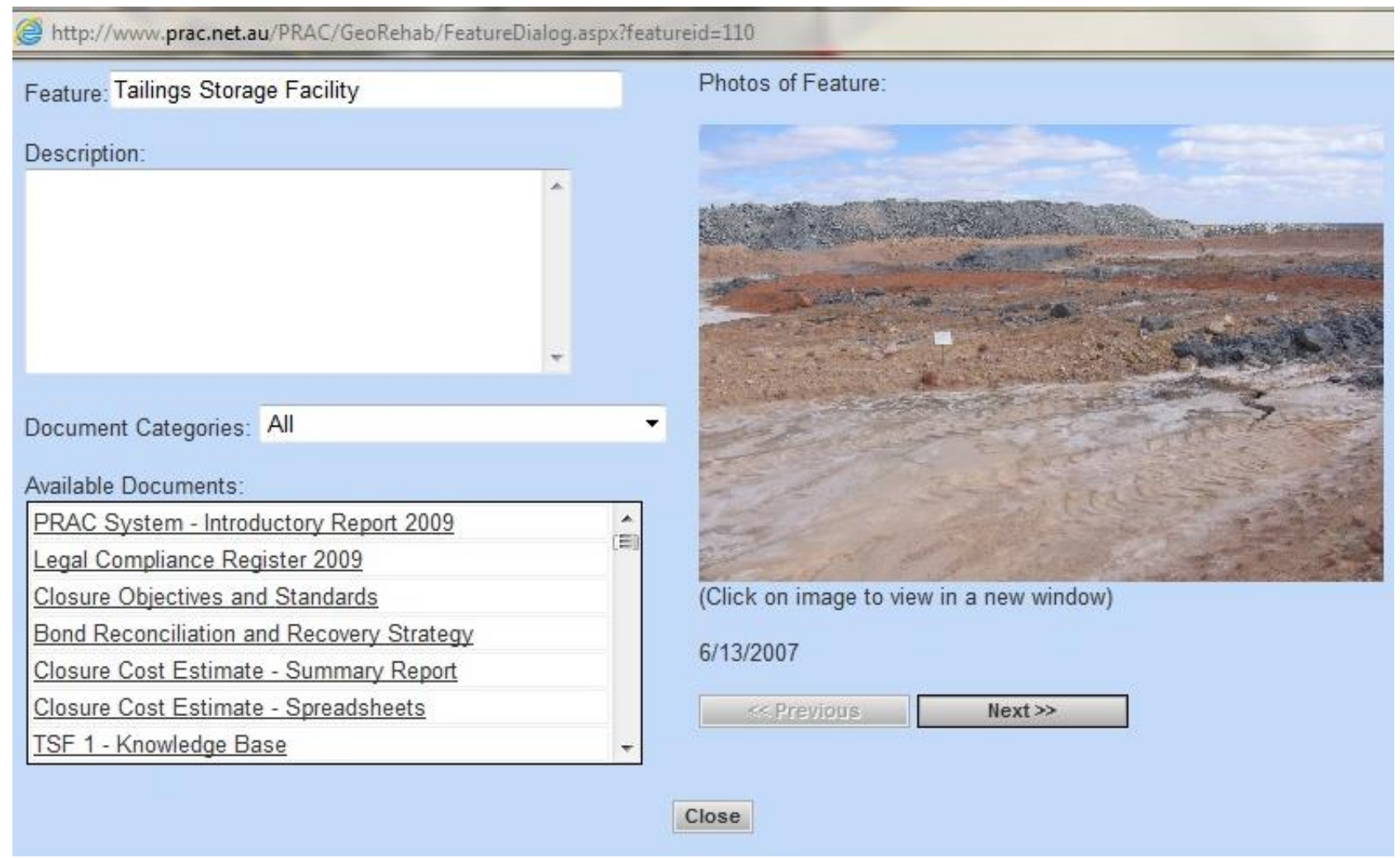

\section{Figure 4 Tailings storage facility information within the PRAC ${ }^{\circledR}$ system for the Challenger Mine}

\subsection{Electronic task registers}

Electronic task registers have many advantages over hardcopy-style task registers. Electronic task registers are by definition more dynamic than 'static' document-based registers as they can be updated quickly and efficiently meaning tasks can always be kept up to date (Figure 5).

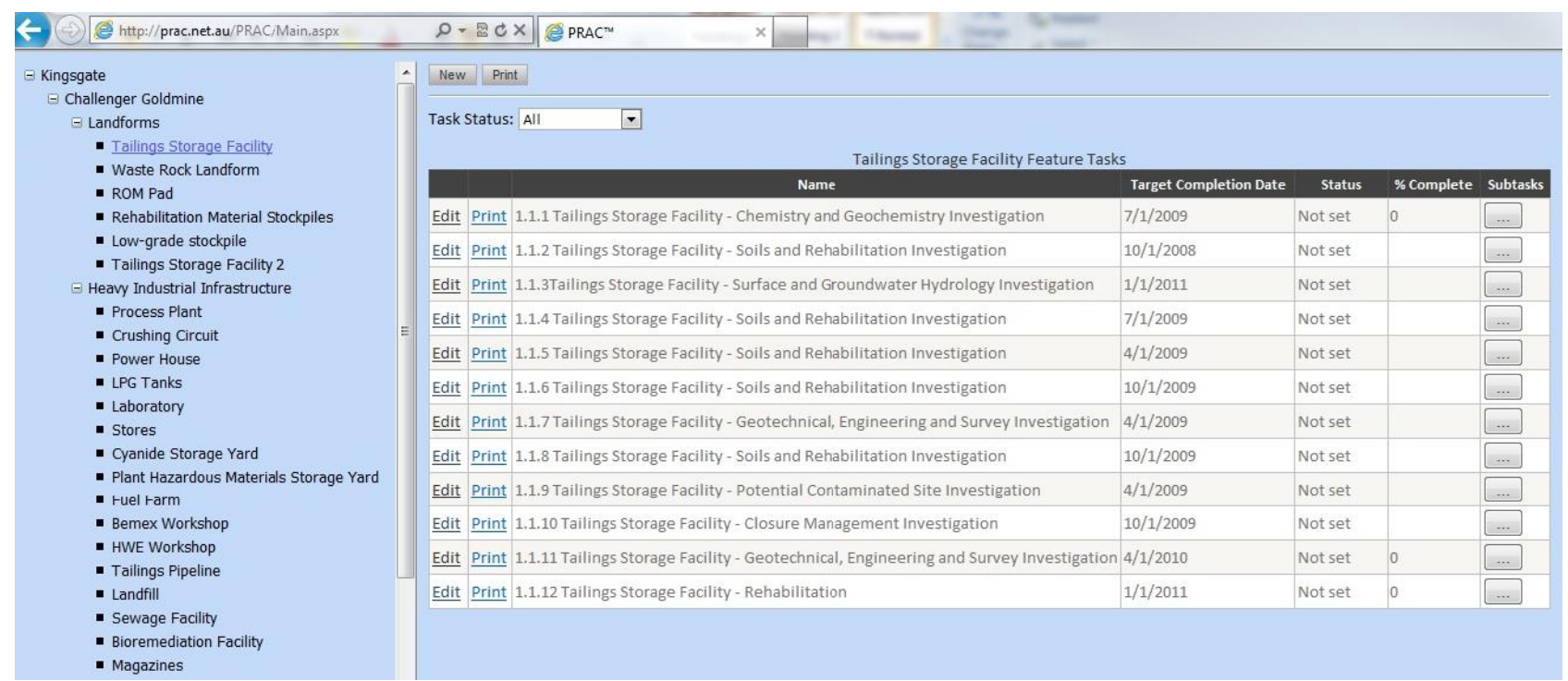

Figure 5 Task register for tailings storage facility within the PRAC ${ }^{\circledR}$ system for the Challenger Mine 
An added advantage of an electronic task register is that it offers more flexibility and control over prioritising tasks during the mine's life. When combined with software for managing rehabilitation and closure budgets, electronic task registers also enable personnel to have greater control in managing rehabilitation and closure costs.

\section{Conclusion}

With mine closure planning requirements becoming increasingly more rigorous worldwide, effective planning for mine closure is now more of a priority for organisations. Given the complexity of mines, successful development of a MCP is reliant on a systematic and integrated planning process that starts during project planning and continues throughout the life of mine.

Reliable data management is a key component in being able to take a well-developed MCP and refine it during operations and ultimately relinquish the mine to the satisfaction of the regulators. A large amount of data is required to be collected through the whole life cycle to validate rehabilitation performance against agreed criteria. Electronic tools exist and are becoming increasingly common to assist with the management and reporting of this data. Tools include consolidated databases to ensure all closure related information is centralised, GIS technologies to define and store domain specific information and electronic task registers that enable rehabilitation and closure implementation to be conducted more efficiently. These tools mean the new legislative requirement need not be an operational burden.

\section{Acknowledgement}

The author would like to acknowledge Kingsgate Pty Ltd for allowing their data to be presented in this paper.

\section{References}

Australian and New Zealand Minerals and Energy Council (ANZMEC) and Minerals Council of Australia (MCA) (2000), Strategic Framework for Mine Closure, National Library of Australia Catalogue Data.

Bentel, G.M. (2009) Key Closure Planning Considerations, in Proceedings Fourth International Conference on Mine Closure (Mine Closure 2009), A.B. Fourie and M. Tibbett (eds), 9-11 September 2009, Perth, Australia, Australian Centre for Geomechanics, Perth, pp. 41-54.

Clark, A.L. and Cook Clark, J. (1999) An International Overview of Legal Frameworks for Mine Closure, viewed 6 May 2012, http://www.elaw.org/system/files/11198931391clark_jcclark.pdf.

DMP (2011) Department of Mines and Petroleum. Guidelines for Preparing Mine Closure Plans, dated June 2011, Western Australian Government, p. 3, p. 20, p. 22, p. 27, p. 32, p. 70, p. 72.

DITR (2006a) Department of Industry Tourism and Resources. Mine Closure and Completion Handbook, Australian Commonwealth Government, p. 1, p. 15.

DITR (2006b) Department of Industry Tourism and Resources. Mine Rehabilitation Handbook, Australian Commonwealth Government, p. 65.

Friedel, A., Birch, S., Kentwell, J., Moiler, K. and Yáñez, B.M. (2012) Keeping it simple: selecting appropriate vegetation-based completion criteria for mine site rehabilitation, In Proceedings of Workshop on Environmental Management, May 2012, Kalgoorlie, Western Australia.

Jasper, D. and Braimbridge, M. (2008) Waste Characterisation for Optimal Landforms, In Proceedings of Workshop on Environmental Management, May 2008, Kalgoorlie, Western Australia.

South Australian Government (2007) City of Charles Sturt Community Engagement Model, viewed 12 May 2012, http://www.charlessturt.sa.gov.au/webdata/resources/files/Community_Engagement_Model.pdf.

USEPA (2011) United States Environmental Protection Agency. Biological Indicators of Watershed Health - Data Management, viewed 7 July 2012, http://www.epa.gov/bioiweb1/html/data_management.html.

Western Australian Department of State Development (2009), Stakeholder Consultation Information sheet, viewed 10 April 2012 , http://www.dsd.wa.gov.au/documents/000098.siobhan.lynch.pdf. 